\title{
Spokespersons, negotiators and actuators. The invisible workers of pervasive healthcare.
}

\author{
Enrico Maria Piras \\ e-Health unit \\ Fondazione Bruno Kessler \\ Trento, Italy \\ piras@fbk.eu
}

\author{
Alberto Zanutto \\ Dipartimento di Sociologia e Ricerca Sociale \\ Università di Trento \\ Trento, Italy \\ alberto.zanutto@unitn.it
}

\begin{abstract}
The increasing availability of miniaturized instruments able to collect, process, and share personal health information is a distinctive feature of new models of pervasive selfcare. However, pervasive care requires that such instruments can also accompany patients in places where their presence is not well accepted (e.g. school classrooms). In this study we focus on the invisible work necessary for such instruments to be available to the patient in those contexts. Drawing on experience acquired during research on the forms of management of type-1 diabetes among children of school age, we show that pervasiveness is not an intrinsic property of technological instruments but is instead the performative result of action by spokespersons, negotiators and actuators. This finding invites reflection on the fact that pervasiveness is a temporary accomplishment realized through the construction of hybrid networks of norms, actions, technological instruments, and human actors.
\end{abstract}

Keywords; organizational boundaries, hybrid network, personal health information management, invisible work, diabetes, pervasive healthcare.

\section{INTRODUCTION}

The significant attention paid to pervasive healthcare technologies is framed in a context of increasingly marked forms of delegation of self-monitoring and self-management activities from healthcare systems to the patients. The availability of miniaturized instruments able to collect, process, and share personal health information makes it possible to imagine scenarios in which the management of a person's health can come about in any place and at any time, with notable advantages for the chronically sick. To this end, research and development seek to reduce the barriers to the adoption of technologies by producing tools easier to use, less costly, and more closely integrated with other personal devices. Such scenarios mechanically connect technical progress in the field of consumer health informatics to new prospects for everyday healthcare management. Notwithstanding such efforts, however, it is evident that scenarios envisaged in laboratories are rarely fully realized in real-life contexts.

This paper concentrates on the semantic ambiguity of healthcare instruments once they become located outside their design contexts. We shall focus in particular on how technologies change their meanings when they cross organizational boundaries, and on the invisible work of resymbolization performed by patients, family members, and healthcare practitioners to render them acceptable in different contexts of use by acting as spokespersons, negotiators, and actuators of pervasive healthcare technologies.

These reflections stem from a five-year project aimed at developing personal health records [1-4] and to test pervasive instruments for the management different chronic conditions (type-1 diabetes, youth asthma, chronic heart failure). To illustrate our reflections in brief, in the present paper we will make explicit reference only to the case of type-1 diabetes among children of school age. The study involved 10 families and it was conducted through the qualitative analysis (semistructured interviews) of the forms of personal health information management and the appropriation of the technological artefacts used in self-management.

\section{THE INVISIBLE WORK OF PATIENTS}

As patients manage their conditions, they do not always resort to professionals in the first instance. People use over-thecounter medications, ask friends for advice, help relatives in need, or just call in sick: doctors are consulted only in a relatively small number of cases. Patients significantly relieve doctors of some of their workload, facilitate their work, and coordinate the network of caregivers. Such activities constitute what has been termed "articulation work" [5], the activities aimed at anticipating unintended contingencies and facing the unexpected, but which is nevertheless invisible and not represented in rationalized models of work.

Articulation work in healthcare has received significant attention starting from the studies by Anselm Strauss [5] and Susan Leigh Star [6,7]. Since these concepts have entered research programmes, the most recent analyses have demonstrated that patients perform a central role in health information management. Studies show that people maintain files and keep track on information concerning their health $[1,8,9]$. These hidden activities serve to prepare for the encounter with healthcare personnel, to build a self-image as sick, facilitate the doctors' work, and coordinate carers. However, they are taken for granted by healthcare practitioners. Patients also do invisible work in incorporating new technological instruments into the flow of everyday life. The designing of new technologies rests on the hope that the endusers will automatically appreciate their benefits and will be motivated to use them. It is believed that a well-designed technology will support patients in all moments of their lives and probably in all the places where these develop, according 
to a geography of responsibilities assigned by the designer of the technologies [10]. Empirical observation evidences that the adoption of new technologies requires significant articulation work [5], especially in domestic contexts where patients feel themselves primarily responsible for their care. In their homes they perform numerous actions not anticipated by, and not visible to, the healthcare system but which nevertheless have the intensity of outright management [8]. Some researchers, indeed, have conjectured that it is possible to draw up a balance between recognized work and invisible work, especially when it is performed within private life settings [11,12]. Finally, other studies $[1,8]$ have shown that the action model adopted by patients is the outcome of a hybrid network comprising their different life-settings and the relationships that connect their choices with the surrounding environment.

Analysis of invisible work shows the complexities involved when new technologies are adopted, and it serves to promote their correct evaluation $[7,13,14]$. Invisible work is particularly interesting when undertaken to make a brand-new technology, which requires at least an idea of the practices that it is intended to support/replace and the context in which these practices are performed - with particular regard to the physical places in homes dedicated to health management and the particular networks that technologies help to support [1]. In the case of chronic diseases this complexity is heightened because the patients do not only travel between home and hospital, with the consequences just described. Difficulties may also arise when the patients are at school, on a journey, at work, or on holiday and must continue to use devices designed for a healthcare setting and according to a healthcare logic [15]. Other studies have termed these different ways to configure devices a 'technogeography of care', a network of places presupposing a diversity of contexts and meanings conveyed by the assistive technologies themselves [16]. Hence, once the technologies have been introduced, they generate unintended and unpredictable forms of work redistribution among medical personnel $[17,18]$ but also between doctors and patients [19]. As a consequence, supporting invisible articulation work requires specific studies which follow subjects and describe their practices in the manifold contexts of use, paying attention to the strategies with which care is made possible despite the limitations imposed by the context.

\section{SPOKESPERSONS, NEGOTIATORS, ACTUATORS. THE INVISIBLE WORKERS OF PERVASIVE HEALTHCARE}

The onset of a chronic disease requires patients to familiarize themselves with new objects that will accompany them for the rest of their lives in the various places of the pathology's management. Whether these are measurement instruments, communication technologies, or medicines, patients are educated to understand what their purposes are and how to use them correctly. The taken-for-granted of patient education is that the sick are able to create a space for these objects in their everyday lives, finding physical locations for them, constructing routines for their use in the flow of everyday activities. Not always are patients able to perform this task delegated to them by the healthcare institutions, so that intervention by spokespersons, negotiators, and the actuators of the objects is necessary. Spokespersons, negotiators, and actuators are not necessarily different people. The same person can perform several functions, and the role may change over time. Using the terms 'spokesperson', 'actuators', and 'negotiators' is a simplification which personalizes a process

\section{A. Spokesperson}

Technologies do not speak on their own behalf; they do not explain by themselves what they are and what their purpose is. But above all, no object possesses a meaning extraneously to the context in which it is situated. Pervasive health technologies are no exception. Whilst their meaning is clear and unambiguous in laboratories, their sense in other contexts depends on work perfumed by spokespersons, these being human actors who undertake to introduce them and make them acceptable to the gatekeepers of the social spaces the technology will need to accompany the person. The spokespersons take action when it is necessary for these to assume an unambiguous and acceptable meaning in the context of use. The role of spokesperson is usually performed by the patients themselves or by their family members. If they are not considered fully credible by the other parties, the role is assumed by the doctors, as recognized and respected figures who authoritatively define the sense of the technical object to the benefit of those around the patient. In the case of diabetes management, for example, the instruments used to measure the glucose level (stick) and to administer insulin (pen) are often denied access to educational settings. The affordances of instruments that contain a needle suggest to teachers and school administrators that they are objects dangerous for the patient and his/her schoolmates. When this happens, the doctors must perform accompaniment work whereby finger sticks and glucometers are redefined as essential healthcare instruments that must be constantly available to the diabetic.

The scope of the spokeperson's action cannot be defined $a$ priori because it depends on responses by the contexts in which the patient's everyday routine takes place, and which react in unpredictable ways. In one case, the parents of a diabetic child had been able on their own to make the teachers at his nursery school understand his needs without having to summon the doctor. Unexpectedly, the problem arose with another organization, which managed the child's transport to school.

I know about a boy who they wanted to stop using the school bus to go to nursery school because he's diabetic. The association's doctor had to go and explain and reassure everybody. They almost wanted not to accept a child like that.

The interpretative ambiguities on the meaning of instruments do not necessarily arise in organizational contexts alone; they may also do so within the family, as testified by the unpredictable reaction of the brother of a young diabetic girl.

We've had some problems with her little brother. At home he was very good, but at school he misbehaved and kept on talking about diabetes. He thought that his sister was taking drugs. The doctor had a talk with him to solve the problem.

\section{B. Negotiators}

The 'spokespersoning' of instruments and patients is sometimes not enough. Organizations may refuse to give access to technologies and patients. In this cases the work of the spokesperson does not grant access and use to the technologies. The reasons for opposing a care technology may 
be very different, but they are often connected with the fact that a person must perform care-related operations which are not countenanced by the organization. In this cases the intervention of negotiators is required. Negotiators undertake the task of reconciling the patient's healthcare needs with respect for the norms that regulate organizational life, or of negotiating exceptions to those norms. The distinction between spokesperson and negotiator is subtle but important. Spokesperson speaks of behalf of the technical object and the patients, presenting their needs and leaving to organization the burden to accommodate them into the daily routines. For a negotiation to take place at least two negotiators are involved. Through collaboration and conflict negotiators of both sides, patients and organizations, work to define how, when and by whom the technologies can be used inside the organizational boundaries. The outcome of the negotiation is ultimately what defines the degree of pervasiveness of technology and care.

If organizations allow patients to use technology as they wish the distinction between spokespersons and negotiators is minimal. A recurrent case concerns the use of cell phones in school classrooms. The negotiator may obtain an exemption from the school rule prohibiting the use of cell phones by children when $s /$ he is able to convince the teachers and school administrators that cell phones are not gaming technologies but devices necessary to maintain contacts with caregivers (the family). In this case, the figures of the negotiator and the spokesperson tend to converge. More interesting are cases in which explaining the needs of the patients and the role of technologies ('spokespersoning') is not enough and the negotiation process generates more intricate mediations with outcomes where exceptions to the rules are less broad. An example is provided by the case of the use of a glucometer by a girl attending nursery school.

There was a shelf with a flap closed with a padlock, where we put her satchel. When she needed to use the finger stick, she asked the teacher and went to get her satchel.

In this case one negotiator (the father) was able to have the glucometer admitted into the nursery school and to have the child's capacity to use it autonomously recognized. In exchange, he accepted that the device would not be with the girl in the classroom but instead be kept in a space controlled by the teachers (the other negotiator). As this example shows, healthcare technologies are not intrinsically pervasive; rather, they become so in relation to their acceptability in the contexts of use imagined in the laboratory.

The importance of the negotiators is testified by cases in which he/she fails to find a compromise between the different exigencies of the patient and the organization. In this case, ensuring that the patient has access to his/her healthcare management instruments may require a drastic solution.

There was a problem [with using the glucometer in class], but it was due to a specific teacher. So we changed her section.

\section{Actuators}

Pervasive technologies do not act automatically; they often have be set and manoeuvred by competent people. The level of competence, however, is not defined once and for all, but instead depends on the context. A child who enjoys the confidence of his/her parents in use of a glucometer may not be considered capable of doing so by the teachers, who may require that others handle the device in the school. In this case, care is made pervasive by identifying a person who is given the task of activating the instrument in the stead of the patient when s/he is unable or unauthorized to do so personally. We shall refer to this person as an 'actuator', borrowing the term from engineering, where it denotes a mechanism operated by a control system. The actuator of a pervasive health technology is a human or a set of humans spatially close to the patient and able to ensure, upon request, the execution of a task which requires the use of the health technology.

In the case of very young diabetic patients, the actuator may be a teacher trained to measure the child's glycaemia level and communicate it by telephone to his/her parents. More often the actuators are the parents themselves, who are required to undertaken direct management of all the care instruments.

I and my husband had to be ready to go and give the insulin at the nursery school. If the teachers called both of us had to be able to give the injections.

The mediation process often centres on negotiating responsibilities for use of the care technologies (e.g. glucometers, medicines), and the outcome may consist of complex patterns of realization. In one case, for instance, a boy was authorized to measure his glycaemia but not to inject the insulin nor to use his cell phone. The teacher accepted the task of acting as intermediary between the boy and his family but did not want to assume responsibility for handling the measurement devices and administering the insulin. In this case the boy's glycaemia measurement involved an actuator (teacher) who communicated to another actuator (parent) whether or not she had to go to the nursery school to give the boy an additional insulin dose.

Actuators may change over time, and in the long period they may lose importance as the patient is able and allowed to manage the instrument by him/herself.

The first year when I had glycaemia spikes I called my mother or father to give me the insulin. Since I got the microinfusor there's been a change of management. I now do it on my own.

\section{THE INVISIBLE WORK OF PERVADING SPACES WITH HEALTHCARE TECHNOLOGIES}

The technical objects necessary to deliver forms of pervasive care do not appear by magic in domestic spaces, in hospitals, or in the jacket pockets of patients. Such instruments do not cross the boundaries of schools or buses at will. Within these spaces they do not automatically acquire the right to be used in each and every space, by anyone or at any time. In certain cases, someone has to assume responsibility for explaining their meanings so that their presence is legitimated in a context where it is not envisaged. In other cases, someone must intervene to find a compromise between care provision and the rules of the organizational spaces in which this is to come about. It is sometimes indispensable to define mechanisms to activate the instruments and the persons delegated to use them. Very often, all these things together are essential so that the technical artifacts can cross the organization's boundaries and contribute to forms of pervasive 
healthcare. In this paper we have concentrated on the invisible work performed by human intermediaries in making the management of chronic disease pervasive. This work is invisible, as said, in that it is not considered in formalized job descriptions. We would reiterate that our purpose in deciding to focus on the mundane practices of the spokesperson, negotiators, and actuators of technologies has not been (only) that of fully acknowledging their roles as active subjects in care delivery. Rather, the intention has been to show the precarious, negotiative, and processual dimension of 'pervasiveness'. Analysis of the invisible work of these actors demonstrates that pervasive healthcare is the outcome of negotiation work which leads to partial agreements which may be called into question by unpredictable events. Close observation of the invisible work of spokespersons, negotiators, and actuators evidences that pervasiveness is a social construction that determines the extent to which care artifacts can re-symbolized, exceptions to the rules negotiated, and actuators enlisted. On this work ultimately depends whether a child can keep his/her glucometer in his/her satchel; whether s/he is instead forced to leave it in the custody of a teacher who guards it in a locked cupboard; whether s/he can use it or a parent need to do it; whether s/he is denied access to the school bus; or, finally, whether s/he is forced to change schools in order to engage in selfcare. In the final analysis, pervasiveness results from the construction of a hybrid network of human and non-human actors in which socalled 'pervasive healthcare technologies' are located alongside modified rules, dedicated spaces, informal norms of behaviour, people authorized to use them, pre-established times, and everything necessary to create a space of acceptability for the technologies themselves within an organizational context that did not envisage their existence. Pervasiveness is constructed tinkering with the material affordances of the spaces, norms, meanings, by using what is available in the specific context, finding ways to circumvent obstacles and to align the elements necessary to make care pervasive.

\section{CONCLUSIONS AND LIMITATIONS}

In this paper we have focused on the invisible work necessary for the pervasive management of health. Drawing on experience acquired during research on the forms of management of type-1 diabetes among children of school age, we have shown that pervasiveness is not an intrinsic property of technological instruments but is instead the performative result of action by spokepersons, negotiators and actuators. This finding invites reflection on the fact that pervasiveness is a temporary accomplishment realized through the construction of hybrid networks of norms, actions, technological instruments, and human actors. This paper is based on analysis of a specific condition whose validity is restricted to the context observed. Extension of the paper's findings would require further research in other contexts and on other technologies.

\section{ACKNOWLEDGEMENTS}

This work is part of the TreC Project, financed by the Autonomous Province of Trento and carried out in collaboration with the APSS (local healthcare trust) and FBK..

\section{REFERENCES}

[1] E. M. Piras and A. Zanutto, "Prescriptions, X-rays and Grocery Lists. Designing a Personal Health Record to Support (The Invisible Work Of) Health Information Management in the Household," Comput Supported Coop Work, vol. 19, no. 6, pp. 585-613, Dec. 2010.

[2] C. Eccher, E. M. Piras, and M. Stenico, "TreC - a REST-based regional PHR,” Stud Health Technol Inform, vol. 169, pp. 108-112, 2011.

[3] E. M. Piras and A. Zanutto, "Emotions and personal health information management: some implications for design," Stud Health Technol Inform, vol. 169, pp. 63-67, 2011.

[4] E. M. Piras, B. Purin, M. Stenico, and S. Forti, "Prototyping a Personal Health Record Taking Social and Usability Perspectives into Account," in Electronic Healthcare, P. Kostkova, Ed. Springer Berlin Heidelberg, 2010, pp. 35-42.

[5] A. L. Strauss, S. Y. Fagerhaugh, and B. Suczek, Social Organization of Medical Work Chicago, London: The University of Chicago Press, 1985.

[6] Star, S. L, "The sociology of the invisible: The primacy of work in the writings of Anselm Strauss", in D. Maines (Ed.), Social organization and social processes: Essays in honour of Anselm Strauss New York: Aldine de Gruyter, pp. 265-283, 1991.

[7] S. L. Star and A. Strauss, "Layers of Silence, Arenas of Voice: The Ecology ofVisible and Invisible Work," Comput. Supported Coop. Work, vol. 8, no. 1-2, pp. 9-30, Feb. 1999.J. Clerk Maxwell, A Treatise on Electricity and Magnetism, 3rd ed., vol. 2. Oxford: Clarendon, 1892, pp.68-73.

[8] A. Moen and P. F. Brennan, "Health@Home: the work of health information management in the household (HIMH): implications for consumer health informatics (CHI) innovations," J Am Med Inform Assoc, vol. 12, no. 6, pp. 648-656, Dec. 2005

[9] A. Civan, M. M. Skeels, A. Stolyar, and W. Pratt, "Personal Health Information Management: Consumers' Perspectives," AMIA Annu Symp Proc, vol. 2006, pp. 156-160, 2006.I. S. Jacobs and C. P. Bean, "Fine particles, thin films and exchange anisotropy," in Magnetism, vol. III, G. T. Rado and H. Suhl, Eds. New York: Academic, 1963, pp. 271350.

[10] Akrich, M., "The De-Scription of Technical Objects",in W. Bijker and J. Law (Eds.) Shaping Technology, Building Society: Studies in Sociotechnical Change. Cambridge, Mass, MIT Press, pp. 205-224, 1992.

[11] M. J. Smith and P. Carayon, "New technology, automation, and work organization: Stress problems and improved technology implementation strategies," International Journal of Human Factors in Manufacturing, vol. 5, no. 1, pp. 99-116, 1995.

[12] A. Civan, W. Jones, P. Klasnja, and H. Bruce, "Better to organize personal information by folders or by tags?: The devil is in the details," Proceedings of the American Society for Information Science and Technology, vol. 45, no. 1, pp. 1-13, 2008.

[13] K. Schmidt and L. Bannon, "Taking CSCW seriously," Comput Supported Coop Work, vol. 1, no. 1-2, pp. 7-40, Mar. 1992.

[14] E. Balka, N. Kahnamoui, and K. Nutland, "Who is in charge of patient safety? Work practice, work processes and utopian views of automatic drug dispensing systems," International Journal of Medical Informatics, vol. 76, pp. S48-S57, Jun. 2007.

[15] A. Mol, "What diagnostic devices do: the case of blood sugar measurement," Theor Med Bioeth, vol. 21, no. 1, pp. 9-22, Jan. 2000.

[16] N. Oudshoorn, "How places matter: Telecare technologies and the changing spatial dimensions of healthcare," Social Studies of Science, vol. 42, no. 1, pp. 121-142, Feb. 2012.

[17] L. Cartwright, "Reach Out and Heal Someone: Telemedicine and the Globalization of Health Care," Health (London), vol. 4, no. 3, pp. 347377, Jul. 2000.

[18] M. Mort, C. R. May, and T. Williams, "Remote Doctors and Absent Patients: Acting at a Distance in Telemedicine?," Science, Technology, \& Human Values, vol. 28, no. 2, pp. 274-295, Apr. 2003.

[19] N. Oudshoorn, "Physical and digital proximity: emerging ways of health care in face-to-face and telemonitoring of heart-failure patients," Sociol Health Illn, vol. 31, no. 3, pp. 390-405, Apr. 2009. 